\title{
Acute mental stress impairs insulin sensitivity in IDDM patients
}

\author{
E. Moberg, M. Kollind, P.-E. Lins, U. Adamson \\ Department of Medicine, Danderyd Hospital, Stockholm, Sweden
}

Summary The effect of acute mental stress on insulin sensitivity was evaluated in ten IDDM patients, studied on two occasions (test day and control day) in random order and separated by a period of 1 3 weeks. Mental stress was evoked by a modified filmed version of Stroop's CWT for $20 \mathrm{~min}$. On the control day, the patients were resting quietly during the corresponding period. Insulin sensitivity was estimated by an insulin $\left(0.4 \mathrm{mU} \cdot \mathrm{kg}^{-1} \cdot \mathrm{min}^{-1}\right)$-glucose $\left(4.5 \mathrm{mg} \cdot \mathrm{kg}^{-1} \cdot \mathrm{min}^{-1}\right)$-infusion test (IGIT) for $6.5 \mathrm{~h}$. Mental stress evoked significant responses for adrenaline, cortisol and $\mathrm{GH}$, their respective peak values being $0.27 \pm 0.05 \mathrm{nmol} / \mathrm{l}, 426 \pm 27 \mathrm{nmol} / \mathrm{l}$ and $7.6 \pm$ $1.8 \mu \mathrm{g} / \mathrm{l}$, as well as increases in systolic and diastolic blood pressure and pulse rate The steady-state blood glucose levels, i.e. the mean blood glucose levels 3$6.5 \mathrm{~h}$ after the start of the IGIT, were significantly higher after stress, compared with those on the control day, $10.6 \pm 1.5$ vs $8.7 \pm 1.4 \mathrm{mmol} / \mathrm{l}, p=0.01$, demonstrating impairment of the insulin sensitivity by mental stress. It is concluded that acute mental stress induces a state of insulin resistance in IDDM patients, which can be demonstrated by an IGIT to appear $1 \mathrm{~h}$ after maximal stress and to last more than $5 \mathrm{~h}$. [Diabetologia (1994) 37: 247-251]

Key words Mental stress, insulin sensitivity, diabetes mellitus, insulin-glucose infusion test, Stroop test.
Although there is considerable experience from clinical practice to suggest that stress of different kinds impairs the glucose control in IDDM patients, previous studies concerning the effect of mental stress on the blood glucose control have not yielded conclusive results. Thus, in some of these studies, no effect on the blood glucose levels was recorded [1-3], whereas other investigators reported an increase of the blood glucose in some patients and an unexpected decrease in others [4-6]. To explain this discrepancy, it has been suggested that different blood glucose reactions to mental stress may appear in subjects with type-A and type-B beha-

Received: 26 May 1993

and in revised form: 23 August 1993

Corresponding author: Dr. E.Moberg, Department of Medicine, Danderyd Hospital, S-182 88 Danderyd, Sweden

Abbreviations: IDDM, Insulin-dependent diabetes mellitus; $\mathrm{GH}$, growth hormone; IGIT, insulin-glucose-infusion test; CWT, colour-word test; AUC, area under the curve. viour [4]. Although such a possibility cannot be excluded, it should be pointed out that there are a number of alternative explanations for the contradictory findings of the previous studies. Firstly, the magnitude of the stress applied in one study was too small to yield a detectable hormonal response [2]. Secondly, in all previous studies, blood glucose was measured no longer than $2 \mathrm{~h}$ after stress provocation. Since $\mathrm{GH}$, one of the possible mediators of stress-induced insulin resistance, induces its effect after a lag period of 3-4 h [7], such protocols appear to be insufficient with respect to $\mathrm{GH}$. Finally, in the majority of the studies, plasma insulin levels were not reported and, hence, convincing assessments of insulin sensitivity were not presented.

The aim of the present study was therefore to evaluate the effect of acute mental stress on insulin sensitivity, measured for several hours after stress and determined by a technique previously evaluated in our laboratory in IDDM patients. 
A

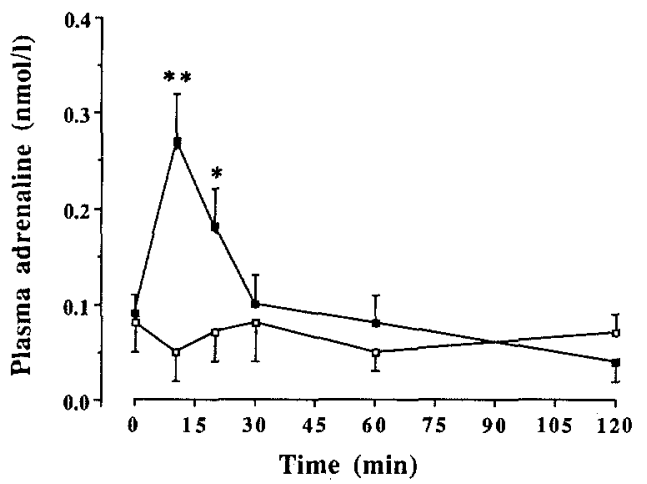

C

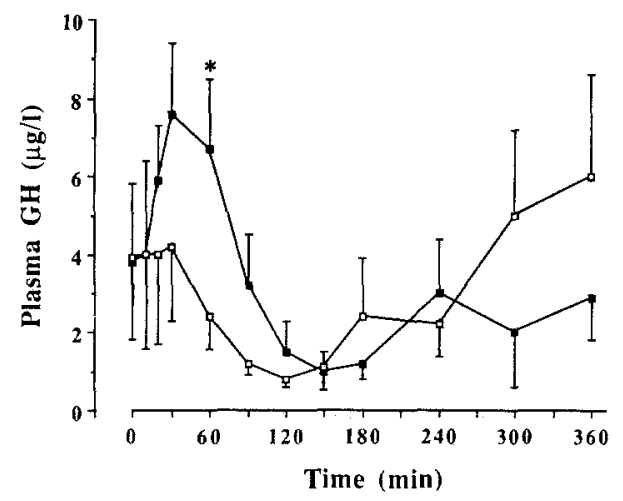

B

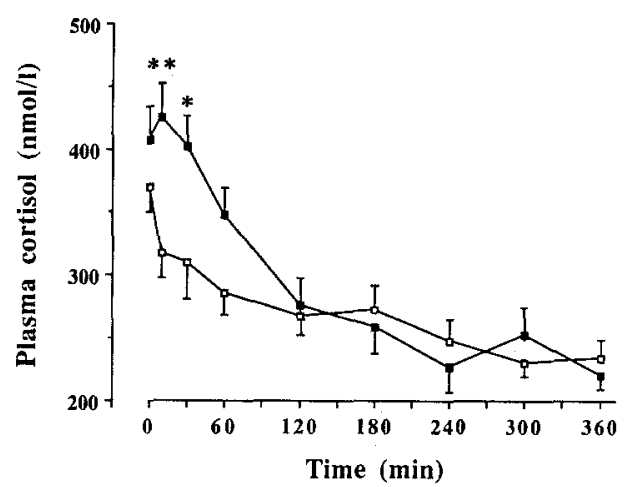

D

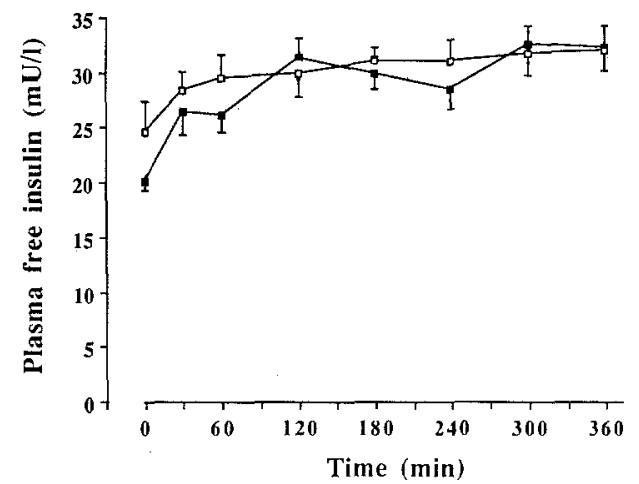

Fig.1A-D. Venous plasma levels of adrenaline (A), cortisol (B), GH (C) and free insulin (D) during mental stress ( and the control day ( $\square$ ). ${ }^{*} p<0.05$, ** $p<0.01$. The increasing GH levels at the end of the control test were caused by spontaneous GH spikes in three of the patients

\section{Subjects and methods}

Ten IDDM patients, seven men and three women, agreed to participate in the study, which was approved by the local ethical committee. The median and range (the latter in parentheses) for age was 47 (19-71) years, for duration of diabetes $13(3-64)$ years, for body mass index $22.7(17.5-27.0) \mathrm{kg} / \mathrm{m}^{2}$, for mealstimulated plasma C-peptide level $0.09(0-0.32) \mathrm{nmol} / \mathrm{l}$, for insulin dose $0.64(0.29-0.72) \mathrm{U} \cdot \mathrm{kg}^{-1} \cdot \mathrm{day}^{-1}$ and for $\mathrm{HbA}_{1 \mathrm{C}} 7.4$ $(5.6-9.9) \%$. The patients were not selected because of a previous history of marked glycaemic lability. Five of them had background retinopathy and one had incipient nephropathy, i.e. a urinary albumin excretion rate over $20 \mu \mathrm{g} / \mathrm{min}$ and normal serum creatinine levels. None of the participants had clinically apparent neuropathy or other medication than insulin.

Intermediate-acting insulin was withdrawn $36 \mathrm{~h}$ before each test. The patients were admitted to the metabolic ward $15 \mathrm{~h}$ before the test, and during this period, their blood glucose was controlled by a variable $i$. v. infusion of short-acting insulin, aiming at a blood glucose level between 5 and $10 \mathrm{mmol} / \mathrm{l}$ during the evening and the night before the test and at $5 \mathrm{mmol} / \mathrm{l}$ at the start of the test the following morning. The patients had their regular meals and snacks, but no food was eaten after 22.00 hours. Thirty minutes before the test the patients were placed in a comfortable semi-recumbent position and a short teflon catheter for blood sampling was inserted into a forearm vein. Each subject was studied on two occasions in random order, separated by a period of 1-3 weeks.

Mental stress was evoked by a modified filmed version of Stroop's CWT lasting for $20 \mathrm{~min}$ [8]. During this test, four colour words (red, yellow, green, blue) were written in incongruent colours on a film screen and, at the same time, a voice presented another colour word. The words were presented randomly and at a variable speed. The subjects were asked to note on a form the colour they saw and to ignore the irrelevant information. During the control day, the patients were resting quietly in a semi-recumbent position. The CWT and the control test were started at the same time of day ( 09.00 hours).

Insulin sensitivity was measured by an insulin $(0.4 \mathrm{mU}$. $\mathrm{kg}^{-1} \cdot \mathrm{min}^{-1}$, Actrapid, Novo Nordisk A/S, Copenhagen, Denmark)-glucose $\left(4.5 \mathrm{mg} \cdot \mathrm{kg}^{-1} \cdot \mathrm{min}^{-1}\right)$-infusion test (IGIT) [9]. We have previously evaluated this method by performing two IGITs, separated by 2 weeks, in 18 ( 8 men and 10 women) IDDM patients. The coefficient of variation was $9 \%$ [10]. The IGIT was started at the beginning of the CWT and at the start of the control test respectively and continued for $6.5 \mathrm{~h}$. The steadystate blood glucose level, $\mathrm{i}$. e. the mean blood glucose level recorded 3-6.5 h after the onset of the IGIT, as well as the AUC for blood glucose, $i$. e. the area enclosed by the blood glucose curve above the baseline level, were used as measures of the insulin sensitivity.

Venous blood samples for the analyses of glucose, free insulin, adrenaline, noradrenaline, GH and cortisol were obtained every 10-30 min, adrenaline and noradrenaline for $120 \mathrm{~min}$ and the other hormones for $360 \mathrm{~min}$. Heart rate and arterial blood pressure were measured intermittently.

The AUC for the different hormones was calculated, for adrenaline from 0 to $30 \mathrm{~min}$, for cortisol and $\mathrm{GH}$ from 0 to $120 \mathrm{~min}$. The differences of the AUC for glucose and the hormones during the CWT, compared with the control test, are referred to as the $\Delta$-values.

Venous blood glucose was measured by a glucose analyser (Yellow Springs Instruments, Yellow Springs, Ohio, USA). The intra-day coefficient of variation of blood glucose measured by this analyser was $1.4 \%$ [11]. Catecholamine levels in plasma were determined by HPLC with electrochemical detection [12] and plasma free insulin was assayed by RIA according to the method of Nakagawa et al. [13], using a commercial kit (Hoechst 
$\mathrm{AG}$, Frankfurt, Germany). Plasma GH was analysed by fluoroimmunometric assay, using monoclonal antibodies (Kabi Pharmacia AB, Uppsala, Sweden) with a detection limit of $0.4 \mu \mathrm{g} / \mathrm{l}$ and an intra- and inter-assay coefficient of variation of $4-6 \%$. Plasma cortisol [14] and C-peptide [15] were determined by RIA.

\section{Statistical analysis}

The Wilcoxon signed-ranks test for paired measurements and the Spearman rank-order-correlation coefficient were used in the statistical analyses. Unless otherwise stated, the data are expressed as means \pm SEM. A $p$ value less than 0.05 was considered as statistically significant.

\section{Results}

The mean blood glucose levels during the $15 \mathrm{~h}$ of i.v. insulin infusion prior to the CWT and the control test were almost identical, $9.1 \pm 0.4 \mathrm{mmol} / 1$ vs $9.2 \pm$ $0.4 \mathrm{mmol} / \mathrm{l}$, and no hypoglycaemic events were recorded. The blood glucose levels at the start of the test were also almost identical, $5.2 \pm 0.3 \mathrm{mmol} / \mathrm{l}$ on the CWT day and $5.3 \pm 0.2 \mathrm{mmol} / 1$ on the control day. The plasma levels of adrenaline, cortisol and $\mathrm{GH}$ were higher during the CWT, compared with the control test (Fig. 1 A-C), whereas there were no differences between the plasma levels of noradrenaline during the two tests (mean plasma levels $2.6 \pm 0.4$ vs $2.1 \pm$ $0.3 \mathrm{nmol} / \mathrm{l}, p=0.17$ during the CWT and the control test, respectively). The AUC during the CWT day and the control day were, for adrenaline $2.6 \pm 0.6 \mathrm{vs}$ $-0.3 \pm 0.4 \mathrm{nmol} \cdot 1^{-1} \cdot \min , p=0.02$, for cortisol $673 \pm$ 39 vs $555 \pm 28 \mathrm{nmol} \cdot 1^{-1} \cdot \mathrm{h}, p=0.007$ and for $\mathrm{GH}$ $9.5 \pm 1.8$ vs $4.8 \pm 1.8 \mu \mathrm{g} \cdot \mathrm{l}^{-1} \cdot \mathrm{h}, p=0.07$, respectively.

During the CWT, the heart rate increased transiently by $21 \pm 2$ beats/min and the systolic and the diastolic blood pressure increased by $25 \pm 4$ and $12 \pm 2 \mathrm{~mm} \mathrm{Hg}$, respectively, whereas the pulse and blood pressure were unaltered during the control day.

The mean plasma levels of free insulin were similar during the two tests, $29.6 \pm 1.0 \mathrm{mU} / \mathrm{l}$ during stress and $30.5 \pm 0.5 \mathrm{mU} / \mathrm{l}$ during the control day, NS (Fig. 1D).

Significantly higher blood glucose values were present $1 \mathrm{~h}$ after maximal stress $(8.0 \pm 0.8$ vs $6.8 \pm 0.5$ $\mathrm{mmol} / \mathrm{l}, p=0.02$ ) and this could be demonstrated up to 5.5 h later $(11.4 \pm 1.8$ vs $8.9 \pm 1.5 \mathrm{mmol} / 1, p=0.04)$ (Fig. 2), yielding higher steady-state glucose levels after mental stress compared with the control day, $10.6 \pm 1.5$ vs $8.7 \pm 1.4 \mathrm{mmol} / \mathrm{l}, p=0.01$. The AUC was also larger after stress, compared with that on the control day, $28.0 \pm 6.8$ and $17.4 \pm 6.5 \mathrm{mmol} \cdot 1^{-1} \cdot \mathrm{h}$, respectively, $p=0.01$. The higher blood glucose levels after mental stress were also accompanied by a tendency to an increased urinary excretion of glucose $(22.4 \pm 12.4 \mathrm{mmol}$ vs $5.4 \pm 2.7 \mathrm{mmol}$, NS).

There were no significant correlations between the $\Delta$-value for blood glucose, on the one hand and the $\Delta$ values for the hormones, on the other. When different

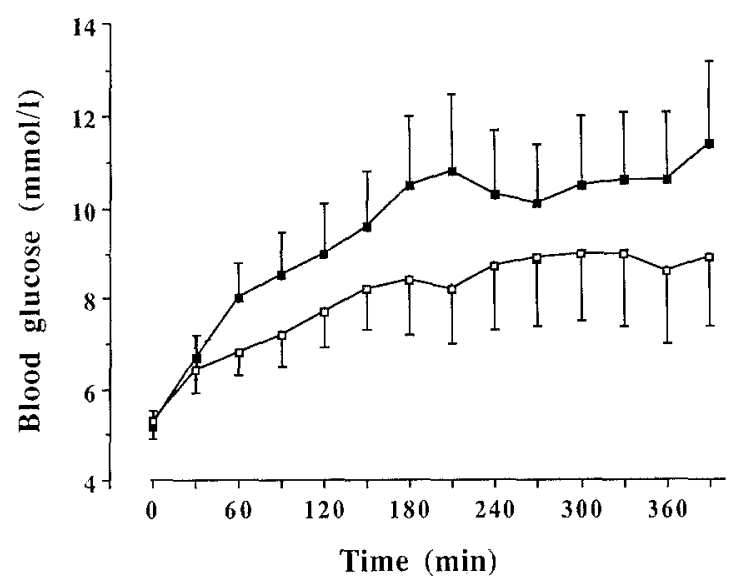

Fig.2. Blood-glucose levels during mental stress (a) and the control day ( $\square$ ). The steady-state blood glucose level, i.e. the mean blood glucose level at 180-390 min, were $10.6 \pm 1.5 \mathrm{mmol} / \mathrm{l}$ after stress and $8.7 \pm 1.4 \mathrm{mmol} / \mathrm{l}$ during the control day, $p=0.01$

parts of the AUC were studied, i. e. before and after $180 \mathrm{~min}$, respectively, there were again no significant correlations between the changes of these areas and the hormonal responses, although there was a tendency to a positive correlation between the change of the glucose area after $180 \mathrm{~min}$ and the cortisol response $(r=0.58, p=0.06)$. Neither was there a correlation between the $\Delta$-value for blood glucose, on the one hand, and the patient's age, the duration of the diabetes, body mass index, $\mathrm{HbA}_{1 \mathrm{c}}$ and insulin dose, on the other, whereas there was a negative correlation between the $\Delta$-value for glucose and the meal-stimulated plasma C-peptide level $(r=-0.61, p=0.048)$.

\section{Discussion}

This study shows that impairment of the insulin sensitivity appears after acute mental stress in IDDM patients within $1 \mathrm{~h}$ after maximal stress and that this effect persists for at least another $5 \mathrm{~h}$.

To our knowledge, insulin sensitivity has not previously been measured by adequate techniques in connection with mental stress in IDDM patients. Instead, in several studies the glycaemic effect of stress was assessed by s. c. injection of insulin, after which the blood glucose response was measured. As there is a large intra-individual variability of s.c. injected insulin [16], which stress itself may also affect [6], it is certainly hazardous to conclude from these studies that there is no influence of mental stress on the blood glucose control. In our study, the blood glucose levels were about $2 \mathrm{mmol} / \mathrm{l}$ higher after stress, compared with the control test. The IGIT method used here has previously been shown to be a sensitive method for the evaluation of insulin sensitivity in IDDM subjects and data from our laboratory suggest that it also has an acceptable coefficient of variation. 
In a recent study, Gonder-Frederick et al. [5] reported an "idiosyncratic" blood glucose response to an active stressor, in that some subjects showed an increase of the blood glucose, whereas in other subjects a decrease of the blood glucose levels was found. In our study, although there were differences in the magnitude of the blood glucose response to stress between the patients, none of them showed a significant decrease of the blood glucose levels after stress, as compared with the control test. It has also been proposed that the characteristics of the stressful event may per se play a role in determining the metabolic response, in so far as stressors requiring processes of active coping seem to affect the metabolic control to a greater extent than do passive stressors [5]. The CWT requires active coping and it induces a highly reproducible, physiological response which resembles the defence reaction.

In our analyses, we found no correlation between the individual hormonal responses to stress and the subsequently increased AUC for blood glucose. This was, however, not unexpected, since it has been considered that the relationship between stress and blood glucose response is essentially non-linear [17] and, furthermore, that the interrelationship between the different stress hormones is a complex one. Thus, previous studies on post-hypoglycaemic insulin resistance are not conclusive whether cortisol alone causes an impairment of the insulin sensitivity, whereas it clearly elicits an amplification of the GH effect in this situation [7, 18]. Moreover, it has been shown that a combined infusion of adrenaline, glucagon and cortisol in physiological doses produces a greater than additive hyperglycaemic response in normal humans [19]. Finally, it is well known that the different stress hormones exert their insulin-antagonistic actions with different time characteristics after stress. Catecholamines and glucagon thus exert their effects mainly during the first $3 \mathrm{~h}$, while GH and cortisol act after a lag period of $3-4 \mathrm{~h}$ and with a duration of several hours $[7,20]$. In the present study, we found a tendency to a correlation between the impairment of the insulin sensitivity during the last hours of the experiment and the cortisol response, but we could not demonstrate such a correlation regarding GH.

The lack of rise of venous noradrenaline during the CWT is consistent with several previous reports [21]. Thus, antecubital venous noradrenaline may not reflect overall sympathetic function, but rather local nerve activity.

Interestingly, we found a significant negative correlation between the impairment of the insulin sensitivity and the meal-stimulated C-peptide level. This suggests that patients without endogenous insulin would be particularly vulnerable to mental stress when the glucose control is considered and that the presence of even small amounts of endogenous insulin may counteract stress-induced insulin resistance. This finding is also in line with previous studies showing that IDDM patients display greater glycaemic responses to adrenaline, cortisol and glucagon [22], as well as GH [23] compared with normal subjects.

Studies of the effect of chronic stress on metabolic control have suggested that anxiety, depression and quality of life show a significant relationship to metabolic control [24] and that daily, stressful life events are correlated with $\mathrm{HbA}_{1 \mathrm{c}}$ [25]. Furthermore, it has been claimed that negative, cumulative stress is correlated with blood glucose levels [26] and that chronic, psychological stress is associated with worse glycaemic control among those who do not cope effectively with stress [27]. In the present study, we induced stress of short duration in a laboratory environment. Furthermore, psychological parameters and personality characteristics were not included in our analyses and, therefore, we have to refrain from speculation on the applicability of our current findings to the understanding of the glycaemic lability of IDDM patients.

In conclusion, this study has shown that acute mental stress induces a state of insulin resistance over several hours in IDDM patients, causing blood glucose levels approximately $2 \mathrm{mmol} / 1$ higher after stress. Further studies are needed to elucidate the role of the individual hormones for this reaction and to find out whether hormone receptor antagonists could reduce the stress-induced hyperglycaemia.

Acknowledgements. This study was supported by grants from the Bert yon Kantzow Foundation and the Swedish Medical Research Council (No.19x-6589). We wish to thank Associate Professor T. Kahan for assistance with the Stroop test and Ms. U.-B.Johansson and Ms. R. Lidbom-Hedin for their skillful technical assistance.

\section{References}

1. Kemmer FW, Bisping R, Steingrüber HJ et al. (1986) Physiological stress and metabolic control in patients with type I diabetes mellitus. N Engl J Med 314: 1078-1084

2. Delamater AM, Bubb J, Kurtz SM et al. (1988) Physiologic response to acute psychological stress in adolescents with type I diabetes mellitus. J Ped Psychol 13:69-86

3. Fernquist-Forbes E, Linde B (1991) Insulin absorption, glucose homeostasis and lipolysis in IDDM during mental stress. Diabetes Care 14: 1006-1012

4. Stabler B, Morris MA, Litton J, Feinglos MN, Surwit RS (1986) Differential glycemic response to stress in type A and type B individuals with IDDM. Diabetes Care 9:550-551

5. Gonder-Frederick LA, Carter WR, Cox DJ, Clarke WL (1990) Environmental stress and blood glucose change in insulin-dependent diabetes mellitus. Health Psychol 9: 503515

6. Greenhalgh PM, Jones JR, Jackson CA, Smith CCT, Yudkin JS (1991) Changes in injection-site blood flow and plasma free insulin concentrations in response to stress in type I diabetic patients. Diabetic Med 9: 20-29

7. Kollind M, Adamson U, Lins PE, Efendic S (1987) Diabetogenic action of $\mathrm{GH}$ and cortisol in insulin-dependent diabetes mellitus. Aspects of the mechanism behind the Somogyi phenomenon. Horm Metab Res 19: 156-159 
8. Frankenhaeuser M, Mellis I, Rissler A, Björkvall C, Pátkai P (1968) Catecholamine excretion as related to cognitive and emotional reaction patterns. Psychosom Med 30: 109-120

9. Heine RJ, Home PD, Poncher M et al. (1985) A comparison of 3 methods for assessing insulin sensitivity in subjects with normal and abnormal glucose tolerance. Diabetes Res 2: 113-120

10. Moberg E, Kollind M, Lins P-E, Adamson U (1993) Variability of blood glucose levels and insulin sensitivity in type 1 diabetic patients. Is there a sex difference? Acta Endocrinol 128: 14 (Abstract)

11. Liu D, Moberg E, Kollind M, Lins P-E, Adamson U, Mac Donald IA (1992) Arterial, arterialized venous, venous and capillary blood glucose measurements in normal man during hyperinsulinaemic euglycemia and hypoglycemia. Diabetologia 35:287-290

12. Hjemdahl P, Daleskog M, Kahan T (1979) Determination of plasma catecholamines by high performance liquid chromatography with electrochemical detection: comparison with a radioenzymatic method. Life Sci 25: 131-138

13. Nakagawa S, Nakayama H, Sasaki T et al. (1973) A simple method for the determination of serum free insulin levels in insulin treated patients. Diabetes 22: 590-600

14. Lantto O, Lindbäck B, Aakvaag A, Damkjaer-Nielsen M, Pomoell U-M, Björkhem I (1983) Assay of cortisol with a radioimmunoassay method calibrated by isotope dilutionmass spectrometry. A Nordic collaborative study. Scand J Clin Lab Invest 43: 433-437

15. Heding LG (1975) Radioimmunological determination of human C-peptide in serum. Diabetologia 11: 541-548

16. Lauritzen T, Faber OK, Binder C (1979) Variation in ${ }^{125}$ I-insulin absorption and blood glucose concentration. Diabetologia 17:291-295

17. Waldhäusl WK, Bratusch-Marrain P, Komjati M, Breitenecker F, Troch I (1992) Blood glucose response to stress hormone exposure in healthy man and insulin dependent diabetic patients: prediction by computer modeling. IEEE Trans Biomed Eng 8: 779-789

18. Fowelin J, Attwall S, von Schenk H, Smith U, Lager I (1989) Combined effect of growth hormone and cortisol on late posthypoglycaemic insulin resistance in humans. Diabetes 38: 1357-1364

19. Shamoori H, Hendler R, Sherwin RS (1981) Synergistic interactions among antiinsulin hormones in the pathogenesis of stress hyperglycemia in humans. J Clin Endocrinol Metab 52: 1235-1241

20. Kollind M, Adamson U, Lins P-E, Hamberger B (1988) Transient insulin resistance following infusion of adrenaline in type 1 (insulin-dependent) diabetes mellitus. Diabetologia 31: $603-606$

21. Hjemdahl P (1990) Physiology of the autonomic nervous system as related to cardiovascular function: implications for stress research. In: Byrne DG, Rosenman RH (eds) Anxiety of the heart. Hemisphere Publishing Corporation, New York Washington Philadelphia London, pp 95-158

22. Shamoon H, Hendler R, Sherwin RS (1980) Altered responsiveness to cortisol, epinephrine and glucagon in insulin-infused juvenile-onset diabetics. A mechanism for diabetic instability. Diabetes 29:284-291

23. Press M, Tamborlane WV, Sherwin RS (1984) Importance of raised growth hormone levels in mediating the metabolic derangements of diabetes. N Engl J Med 310: 810-815

24. Mazze RS, Lucido D, Shamoon H (1984) Psychological and social correlates of glycemic control. Diabetes Care 7:360 366

25. Cox D, Taylor A, Nowacek G, Holley-Wilcox P, Pohl SN (1984) The relationship between psychological stress and insulin-dependent diabetic blood glucose control: preliminary investigations. Health Psychol 3: 63-75

26. Hansson SL, Pichert JW (1986) Perceived stress and diabetes control in adolescents. Health Psychol 5: 439-452

27. Peyrot MF, McMurry JF (1992) Stress buffering and glycemic control. Diabetes Care 7: 842-846 